\title{
In-vitro anti-cancer actions of RU-486 on human melanoma cells based on RU-486 treated, caspase inhibitor rescued and recovered cell growth, adhesion and migration functions
}

\author{
Leder DC and Ramaraj $\mathrm{P}^{*}$ \\ ${ }^{1}$ Department of Biochemistry, Kirksville College of Osteopathic Medicine, A.T.Still University, Kirksville, Missouri, USA \\ ${ }^{2}$ Biomedical sciences student, Resident physician, Plainview Hospital, Plainview, New York, USA
}

\begin{abstract}
RU-486, an abortifacient used in the clinic, had been shown to inhibit human melanoma (BLM) cell growth in-vitro by apoptosis. Addition of pan-caspase inhibitor to RU-486, suppressed apoptosis and partially rescued cell growth. Partial rescue of cell growth prompted to check rescue in terms of other in-vitro functions such as adhesion and migration. Partial rescue in cell growth, adhesion and migration functions by pan-caspase inhibitor, led to check recovery of melanoma cells on their own after treatment with RU-486 and caspase inhibitor (CI). Results indicated that CI rescued cells, recovered better than RU-486 alone treated cells in terms of cell growth and adhesion functions. RU-486 treated cells displayed a slow recovery in terms of cell growth, suggesting the inhibition of cell growth was not completely reversible. Results in terms of cell growth, adhesion and migration functions suggested that RU-486 had the potential to be considered as an anti-cancer agent for melanoma.
\end{abstract}

\section{Introduction}

RU-486 is a synthetic steroid [1] and is a progesterone as well as glucocorticoid receptor antagonist [2]. It is used as an abortifacient [3] in the clinic and is also used in the treatment of hormone dependent cancers such as breast, ovary and prostate $[4,5]$. Our previous study showed that RU-486 inhibited mouse as well as human melanoma cell growth significantly in-vitro [6,7]. But this action was mediated neither through progesterone receptor nor glucocorticoid receptor [7]. The mechanism of inhibition of human melanoma cell growth was due to apoptosis [7]. This result raised the question, whether cell growth could be rescued by the addition of pan caspase inhibitor to the cells. Addition of pan-caspase inhibitor resulted in partial rescue of cell growth by suppressing apoptosis. In addition to decrease in cell growth by RU486, cells were seen floating in the medium during RU-486 treatment. This led us to check whether adhesion function was also affected. Initial adhesion assay showed complete loss of adhesion function after 100 $\mu \mathrm{M}$ treatment of RU-486 for $48 \mathrm{hrs}$. Partial rescue of cell growth by caspase inhibitor (CI) gave the idea to check whether adhesion could also be rescued by the addition of pan-caspase inhibitor. Results of rescue experiments paved the way to check recovery of cells on their own in plain medium after treatment with RU-486 and CI. In order to carry out the experiments, cells were divided into 1) treated group representing treatment with $\mathrm{RU}-486,2)$ rescued group where $20 \mu \mathrm{M}$ pan-caspase inhibitor was added along with RU-486 and 3) recovered group where both treated and rescued cells were allowed to recover in plain medium for first $48 \mathrm{hrs}$ and followed by a second $48 \mathrm{hrs}$ recovery. In-vitro functions such as cell growth, adhesion and migration were compared among three groups to check the potential of RU-486 as an anti-cancer agent. Results indicated that RU-486 treatment affected cell growth, adhesion and migration functions of human melanoma (BLM) cells, suggesting RU-486 had the potential to be considered as an anticancer agent. This observation is significant, as RU-486 is already in clinical use for the treatment of other cancers. Now melanoma also may be included as a target for RU-486 action.

\section{Materials and methods}

\section{Chemicals}

RU-486 (mifepristone), pan caspase inhibitor (CI), Crystal Violet (CV) and paraformaldehyde were all purchased from Sigma Chemical Company, St.Louis, MO. MTT (3-[4,5-Dimethylthiazol2-yl]-2,5-diphenyl tetrazolium bromide), isopropanol were also obtained from Sigma Chemical Company. Fetal bovine serum (FBS), Trypsin-EDTA (1X), and PBS powder were purchased from Atlanta biologicals, Lawrenceville, GA. RPMI and antibiotic/antimycotic solution $100 \mathrm{X}(10,000 \mathrm{I} . \mathrm{U} / \mathrm{ml}$ penicillin, $10 \mathrm{mg} / \mathrm{ml}$ streptomycin, $25 \mu \mathrm{g} / \mathrm{ml}$ amphotericin-B) were purchased from Fisher scientific, Houston, TX.

${ }^{\star}$ Correspondence to: Pandurangan Ramaraj, Department of Biochemistry, Kirksville College of Osteopathic Medicine, A.T.Still University, Kirksville, Missouri, USA, E-mail: pramaraj@atsu.edu

Key words: RU-486, pan-caspase Inhibitor, BLM melanoma cell line, cell growth, adhesion, migration

Received: October 22, 2018; Accepted: November 05, 2018; Published: November 07, 2018 
Ramaraj P (2018) In-vitro anti-cancer actions of RU-486 on human melanoma cells based on RU-486 treated, caspase inhibitor rescued and recovered cell growth, adhesion and migration functions

\section{Growth medium (GM)}

All cell culture works were carried out in RPMI 1640 medium containing $10 \%$ FBS $+1 \mathrm{X}$ Pen/Strep/Ampho. Cell growth was quantitated by MTT assay, as shown in previous papers [6-9].

\section{MTT proliferation assay (10)}

BLM cells were suspended in growth medium (GM) and plated at a density of $1 \times 10^{4}$ cells/well in a 96 well plate. Cells were left overnight at $37^{\circ} \mathrm{C}$ to attach to the plate. Following day, growth medium was replaced by GM containing either RU-486 or CI at different concentrations and incubated for $24 \mathrm{hrs}$. After $24 \mathrm{hrs}$, medium was replaced by $100 \mu \mathrm{l}$ of 1 in 10 diluted (in GM) MTT solution and incubated for another 4 hrs at $37^{\circ} \mathrm{C}$. After $4 \mathrm{hrs}$ MTT solution was removed. MTT was reduced by metabolically viable cells to a colored (purple) water insoluble formazan salt. The purple color precipitate was solubilized by adding $100 \mu \mathrm{l}$ of isopropanol and shaken for $20-30 \mathrm{~min}$ at room temperature. Intensity of resultant purple color was measured at $570 \mathrm{~nm}$ in a SLT spectra plate reader.

\section{Adhesion assay}

After 24 hrs of RU-486 treatment, cells were harvested by digesting with trypsin. Thirty thousand $(30,000)$ cells were added to each well in a 96 well plate. Cells were removed at $0,15,30,45$ and $60 \mathrm{~min}$ intervals and wells were washed with medium to remove any loosely attached cells. Cells which were attached to the plate were fixed with $4 \%$ paraformaldehyde and stained with crystal violet dye $(0.2 \%)$ for 5 min [9]. After 5 min staining, excess CV dye was washed away by PBS. Amount of $\mathrm{CV}$ bound to the proteins was proportional to the number of cells in the well. After briefly drying the wells in air, CV was eluted by adding isopropanol and the intensity of purple color was measured at $570 \mathrm{~nm}$ in a plate reader. For the comparison experiments treated, rescued and recovered cells were incubated for straight $60 \mathrm{~min}$ and then CV binding assay was carried out [9-12].

\section{Migration assay}

After 24 hrs of RU-486 treatment, cells were harvested from petri dishes. Four hundred thousand $(400,000)$ cells were added to wells in a
24 well plate. Cells were allowed to settle and attach to the bottom of the plate. Once the cells were completely attached and confluent, a drill was used to make a circular clearing in the middle of the well. Photograph of the area cleared by the drill was taken. This was considered as 0 hr time point. Cells were incubated in GM for $24 \mathrm{hrs}$. At the end of $24 \mathrm{hrs}$, cells migrated into the circular area were photographed. This was considered as migration after $24 \mathrm{hrs}$ and was compared to the corresponding $0 \mathrm{hr}$ time picture. The area covered by the cells were calculated and expressed as percentage of area migrated by cells using a computer software program $[9,13]$.

\section{Statistical analysis}

All experimental points were carried out in triplicate (3 wells). Each experiment was repeated a minimum of two times to check for consistency in results. Each experimental point was expressed as Mean + SEM. Significance between any two experimental conditions was decided using Student's ' $\mathrm{t}$ ' test to determine the $\mathrm{P}$ value and a $\mathrm{P}$ value of 0.05 or less was considered significant.

\section{Results}

\section{Preliminary recovery cell growth and adhesion assays}

Initially, recovery of cell growth was carried out to check whether the inhibition of cell growth by RU-486 was reversible. Fifty $\mu \mathrm{M}$ of RU-486 48 hrs treated cells, were allowed to recover for $72 \mathrm{hrs}$ in plain medium (GM). After 72 hrs recovery there was a marginal increase in cell growth, indicating that the inhibition of cell growth by RU-486 was not a permanent effect. The difference in cell growth between treated and recovered cells was significant as shown by the p-value (0.040) in (Figure 1A). As lot of cells were seen floating during RU-486 treatment, adhesion was checked after $48 \mathrm{hrs}$ of RU-486 treatment. The assay showed that $100 \mu \mathrm{M}$ of RU-486 treatment completely abolished adhesion (Figure1B), suggesting that adhesion function was also inhibited by RU- 486 treatment. These two preliminary studies laid the foundation for the present research work.

\section{Adhesion dose and time curves}

Preliminary adhesion experiment with $100 \mu \mathrm{M}$ of RU-486 treatment showed complete loss of adhesion. Since adhesion assay was
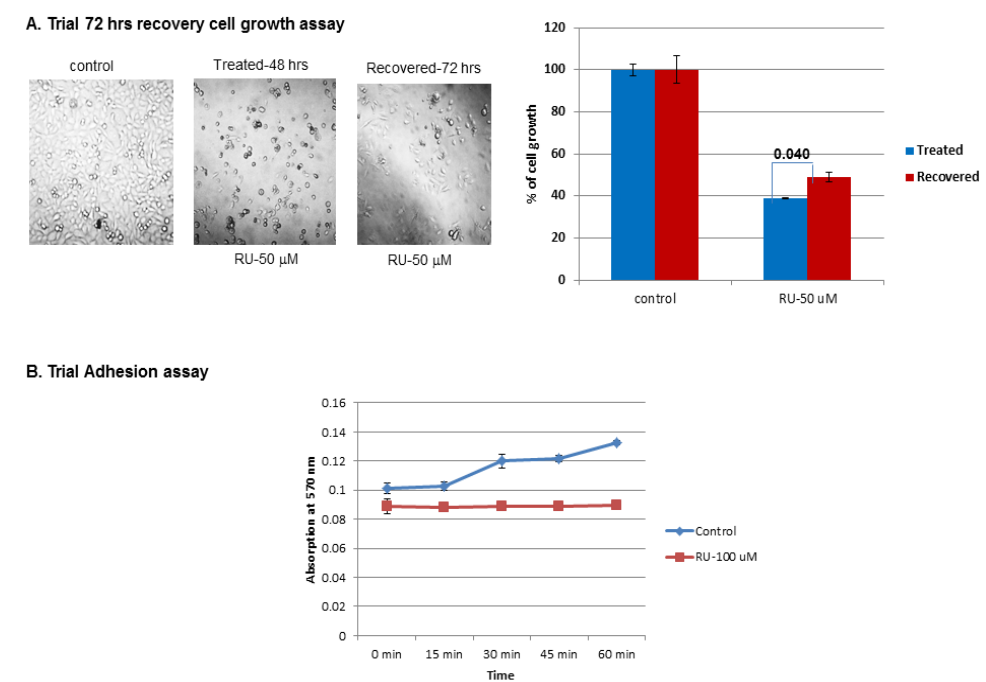

Figure 1. Trial recovery cell growth and adhesion assay: A) Initially cells were treated with RU-486 for 48 hrs. After removal of RU-486, cells were washed with medium and allowed to grow in plain GM for $72 \mathrm{hrs}$. After $72 \mathrm{hrs,} \mathrm{cell} \mathrm{growth} \mathrm{was} \mathrm{assessed} \mathrm{by} \mathrm{MTT} \mathrm{assay.} \mathrm{There} \mathrm{was} \mathrm{a} \mathrm{marginal} \mathrm{increase} \mathrm{in} \mathrm{cell} \mathrm{growth} \mathrm{in} \mathrm{RU-486} \mathrm{treated} \mathrm{cells} \mathrm{with} \mathrm{a} \mathrm{p-value} \mathrm{of} 0.04$. B) As cells were seen floating during RU-486 treatment, adhesion was checked by harvesting cells after $100 \mathrm{uM} \mathrm{RU}-486$ treatment. Thirty thousand cells were added to each well of 96 well plate. Cells were removed at various time points $(0,15,30,45,60 \mathrm{~min})$. Cells which were attached to the plate were quantified by crystal violet binding assay. Untreated control cells displayed a timedependent increase in adhesion. Whereas, RU-486 $100 \mathrm{uM}$ treated cells displayed a flat line indicating complete loss of adhesion 
Ramaraj P (2018) In-vitro anti-cancer actions of RU-486 on human melanoma cells based on RU-486 treated, caspase inhibitor rescued and recovered cell growth, adhesion and migration functions

carried out after $48 \mathrm{hrs}$ of treatment, adhesion at earlier time point of RU- 486 treatment such as 12 and 24 hrs were checked. Adhesion assay showed a time dependent decrease in adhesion and a significant loss of adhesion was observed after $24 \mathrm{hrs}$ treatment of RU-486 (Figure 2A). Since, RU-486 showed a dose-dependent inhibition of cell growth, a dose-dependent loss of adhesion was also checked. Adhesion assays carried out at 10,50 and $100 \mu \mathrm{M}$ concentrations of RU-486, showed a dose-dependent loss of adhesion (Figure 2B) compared to untreated control cells.

\section{In-vitro rescue and recovery studies of human melanoma (BLM) cell growth function}

Initially, in-vitro effect of CI rescue and recovery on cell growth function was studied using a single concentration of RU-486 $(50 \mu \mathrm{M})$.

A. Time dependent decrease in Adhesion

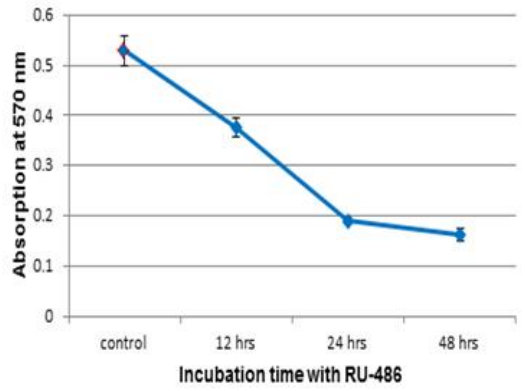

Fifty $\mu \mathrm{M}$ of RU-486 treatment for 24 hrs resulted in $61.5 \%$ cell growth compared to $100 \%$ growth in untreated control cells (Figure 3, Treated). But, CI addition rescued cell growth partially to $72 \%$ with a p-value of 0.009 (Figure 3, Treated). When both treated and rescued cells were allowed to recover for first $48 \mathrm{hrs}$, RU-486 $50 \mu \mathrm{M}$ treated cells showed only a marginal increase in cell growth from $61.5 \%$ to $70 \%$, whereas CI rescued cells showed a significant increase $(95 \%)$ in cell growth (Figure 3, First $48 \mathrm{hrs}$ recovered). Again, when cells were allowed to recover for a second $48 \mathrm{hrs}$, CI rescued cells showed a cell growth of 97\% close to control level. But, RU-486 treated cells showed again a marginal increase in cell growth from $70 \%$ to $77 \%$, (Figure 3, Second 48 hrs recovered). So, recovery of cell growth in CI rescued cells was better than the recovery of cell growth in RU- 486 treated cells. RU- 486 treated

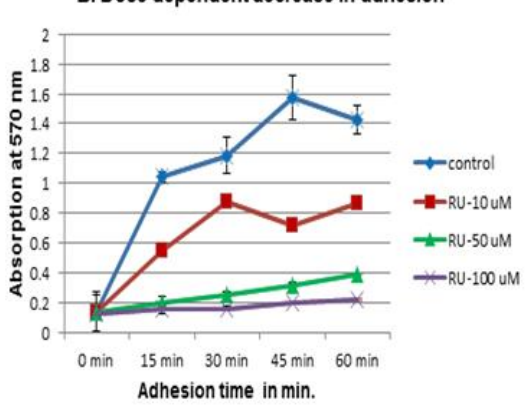

Figure 2. Time and dose-dependent adhesion assay: 2A) In this experiment, effect of incubation time of RU-486 on cell adhesion was determined. RU-486 50 uM was incubated at 12,24 and $48 \mathrm{hrs}$. Cells were harvested and 30,000 cells were incubated in 96 well plate. At the end of $60 \mathrm{~min}$, cells were removed. Cells which were attached to the plate were quantified by CV binding assay. Result indicated a time-dependent decrease in adhesion with significant loss of adhesion seen at 24 hrs. So in subsequent experiments, cells were incubated for 24 hrs with RU-486. 2B) In this experiment cells were incubated separately with 10, 50 and $100 \mathrm{uM}$ concentrations of RU-486. After 24 hrs of incubation, cells were removed and CV binding assay was carried out on the cells attached to the plate. There was a dose-dependent loss of adhesion with a complete loss of adhesion seen at $100 \mathrm{uM}$ concentration of RU-486
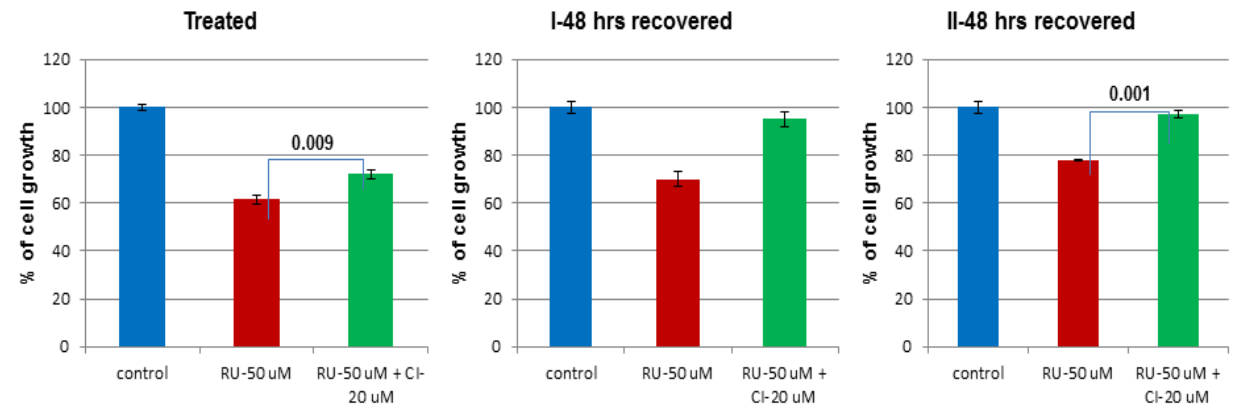

Cell Growth Assay - Comparison of RU-486 treated, CI Rescued and Recovered cells
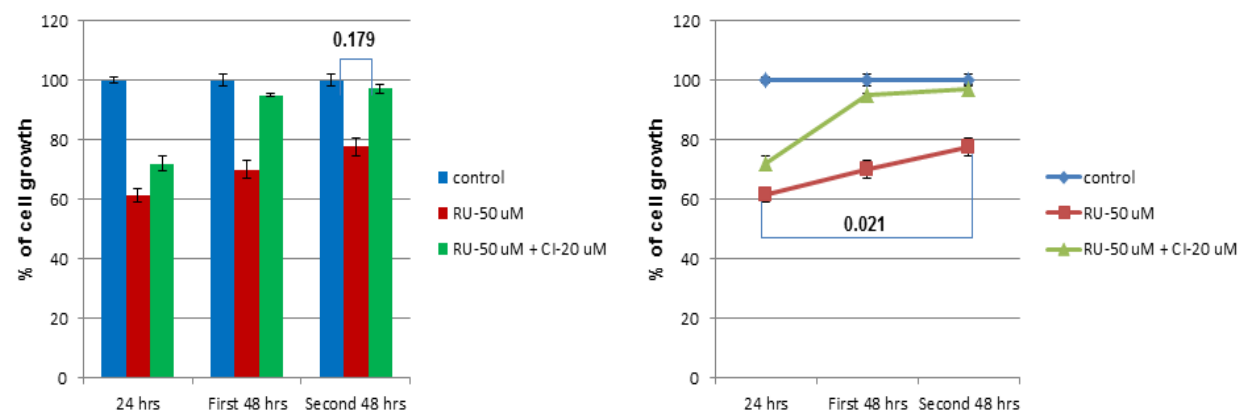

Figure 3. In-vitro rescue and recovery of cell growth function: In order to find out the effect of RU-486 on cell growth \& recovery, one group of cells was treated with RU-486 50 uM and the rescued group of cells was treated with RU-486-50 uM $+20 \mathrm{uM}$ of CI along with untreated control group. Cell growth was quantitated by MTT assay after 24 hrs of treatment with RU486. Cell growth was decreased to $61.5 \%$ by RU-486, whereas CI was able to rescue cell growth to $72 \%$ with a p-value of 0.009 . During first 48 hrs recovery, CI rescued cell growth ( $95 \%$ ) was comparable to control cell growth, whereas, RU-486 treated cells showed only a mild increase in cell growth ( $70 \%)$. When cells were allowed to recover for $2^{\text {nd }} 48$ hrs, CI rescued cells growth $(97 \%)$ was close to control cell growth, but RU-486 treated cell growth (77\%) was again marginal. This was best illustrated in the line diagram 
Ramaraj P (2018) In-vitro anti-cancer actions of RU-486 on human melanoma cells based on RU-486 treated, caspase inhibitor rescued and recovered cell growth, adhesion and migration functions

cells showed a slow recovery of growth and was not able to recover cell growth completely even after 96 hrs recovery.

\section{In-vitro rescue and recovery studies of human melanoma (BLM) cell adhesion functions}

Partial rescue of cell growth by CI, prompted us to check rescue of adhesion function after CI was added. RU-486 $50 \mu \mathrm{M}$ treatment decreased adhesion to $64 \%$ in treated group compared to $100 \%$ adhesion in untreated control group (Figure 4, Treated). But, CI rescued adhesion to $73.9 \%$ in rescued group with a p-value of 0.044 (Figure 4 , Treated). When both treated and rescued cells were allowed to recover for first $48 \mathrm{hrs}$, rescued cells showed improved adhesion (95.5\%) over treated cells (85.6\%) (Figure 4, First 48 hrs recovery). Again, when cells were allowed to recover for a second $48 \mathrm{hrs}$, rescued cells showed a near control level recovery (98.5\%) and treated cells also showed a significant recovery (91\%) in terms of adhesion function (Figure 4, Second 48 hrs recovery), indicating decrease in adhesion function was a reversible effect.

\section{Comparison of rescue and recovery studies in terms of cell growth and adhesion functions}

Comparison of cell growth between control and RU-486 treated cells showed only a partial increase in cell growth even after second 48 hrs recovery (Figure $5 \mathrm{~A}$ ). It implied that the inhibition by RU- 486 could only be partially recovered, but not completely. However, when CI (20 $\mu \mathrm{M}$ ) was added along with RU-486, there was a significant recovery of cell growth in the first $48 \mathrm{hrs}$ recovery itself (Figure 5A). CI rescued cells recovered better in terms of cell growth (Figure 5B). Similarly, when adhesion assays were compared between control and RU-486 treated cells, RU-486 treated cells showed a significant recovery within first 48 hrs itself (Figure 5C). But CI rescued cells recovery within first 48 hrs was close to control level adhesion (Figure 5D). By the end of second $48 \mathrm{hrs}$ recovery, CI rescued cells recovery (98.5\%) was close to control level and RU-486 treated cells recovery (91\%) was also significant (Figure 5D), indicating that the inhibition of adhesion function was a reversible effect. Again, CI rescued cells recovery was better than RU486 treated cells recovery in terms of adhesion function also. Based on the recovery study, it could be speculated that cell growth and adhesion functions did not go hand in hand.

\section{In-vitro rescue study of migration function}

Adhesion was essential for migration of cancer cells, which resulted in metastasis of cancer. As adhesion function was affected by RU-486 treatment, impairment in migration function was anticipated. So, drill migration assay was carried out to check migration function. The differences in migration between untreated control, RU-486 treated and CI rescued cells were shown qualitatively by the picture (Figure 6). Quantitatively, RU-486 $(50 \mu \mathrm{M})$ treatment decreased migration to $23.6 \%$ (with a p-value of 0.001 ) compared to $90 \%$ migration in untreated control cells (Figure 6). However, CI addition partially rescued migration to $35.9 \%$, indicating $\mathrm{CI}$ was able to partially rescue migration function also.

\section{Discussion}

Our earlier study [7] with human melanoma (BLM) cells showed that RU-486 significantly inhibited cell growth by inducing apoptosis and also caused cells to float in the medium during treatment. Initial adhesion assay showed that adhesion was completely lost after $100 \mu \mathrm{M}$
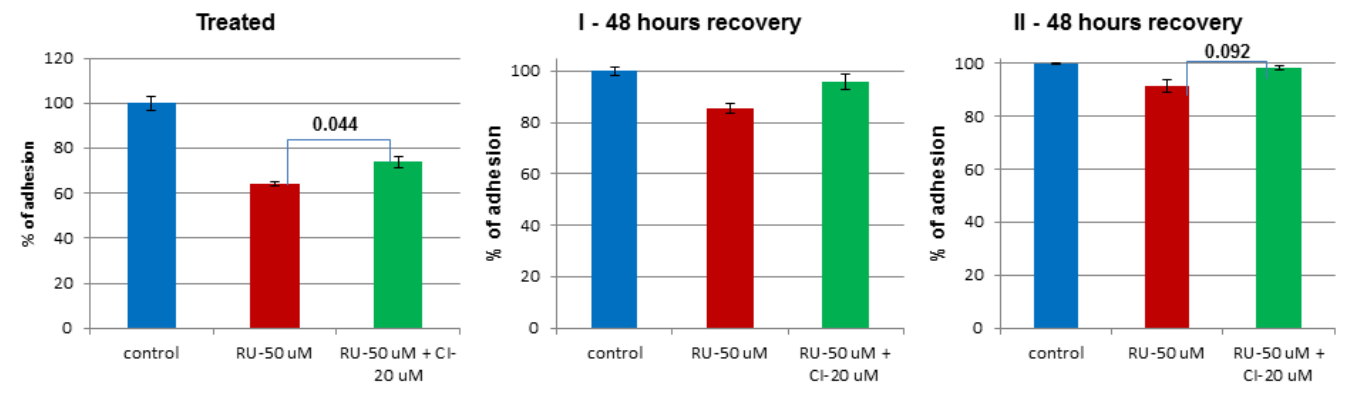

Adhesion assay - comparison of RU-486 Treated, Rescuedand Recovered Cells
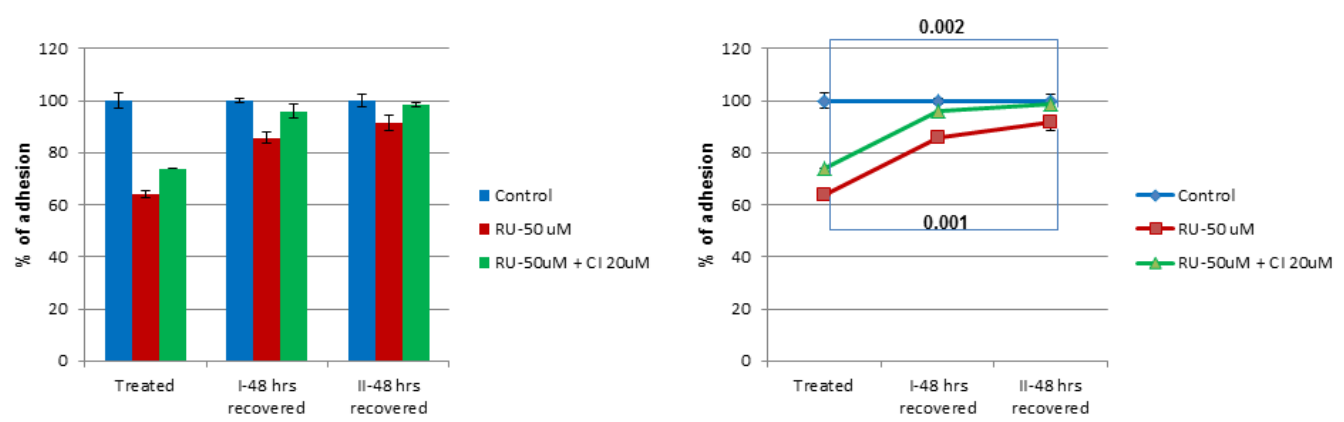

Figure 4. In vitro rescue and recovery of adhesion function: Treated group of cells were subjected to RU-486 (50 uM) treatment and rescued group of cells were treated with RU-486-50 $\mathrm{uM}+\mathrm{CI} 20 \mathrm{uM}$ along with untreated control group. RU-486 decreased adhesion to $64 \%$ compared to control group at $100 \%$. But, CI partially rescued adhesion to $73.9 \%$ with a p-value of 0.044. After first $48 \mathrm{hrs}$ recovery, there was a significant recovery (85.6\%) in adhesion of RU-486 treated cells, whereas CI rescued cells recovery (95.5\%) was close to control cells. After second 48 hrs recovery, there was a further increase in adhesion (91\%) of RU-486 treated cells and CI rescued cells recovery (98.5\%) was near control level, as illustrated in the line diagram. This suggested that inhibition of adhesion was not a permanent effect 
Ramaraj P (2018) In-vitro anti-cancer actions of RU-486 on human melanoma cells based on RU-486 treated, caspase inhibitor rescued and recovered cell growth, adhesion and migration functions
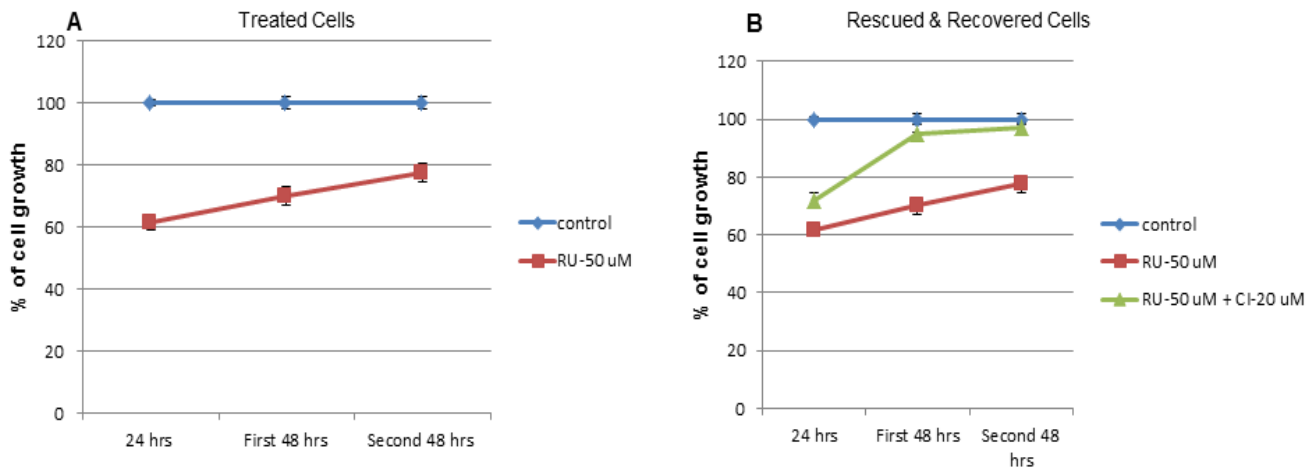

Comparison of adhesion between treated and rescued \& recovered cells
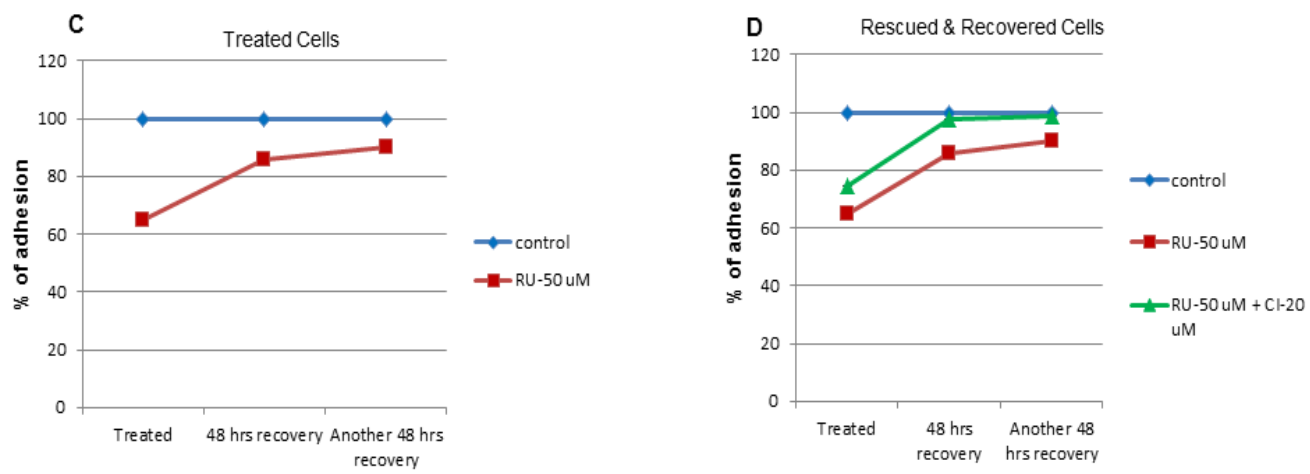

Figure 5. Comparison of rescue and recovery studies in terms of cell growth and adhesion functions: Comparison of cell growth between control and RU-486 treated cells showed a slow recovery and not a complete recovery in terms of cell growth. But, with CI rescued cell, cell growth recovery was significant, suggesting CI rescued cells recovery was better than RU-486 treated cells recovery. Comparison of untreated control and RU-486 treated cells adhesion function showed a significant recovery of adhesion in treated cells after first 48 hrs recovery. However, CI rescued cells recovered adhesion function close to control cell, again suggesting CI rescued cells recovered adhesion function better than RU-486 treated cells
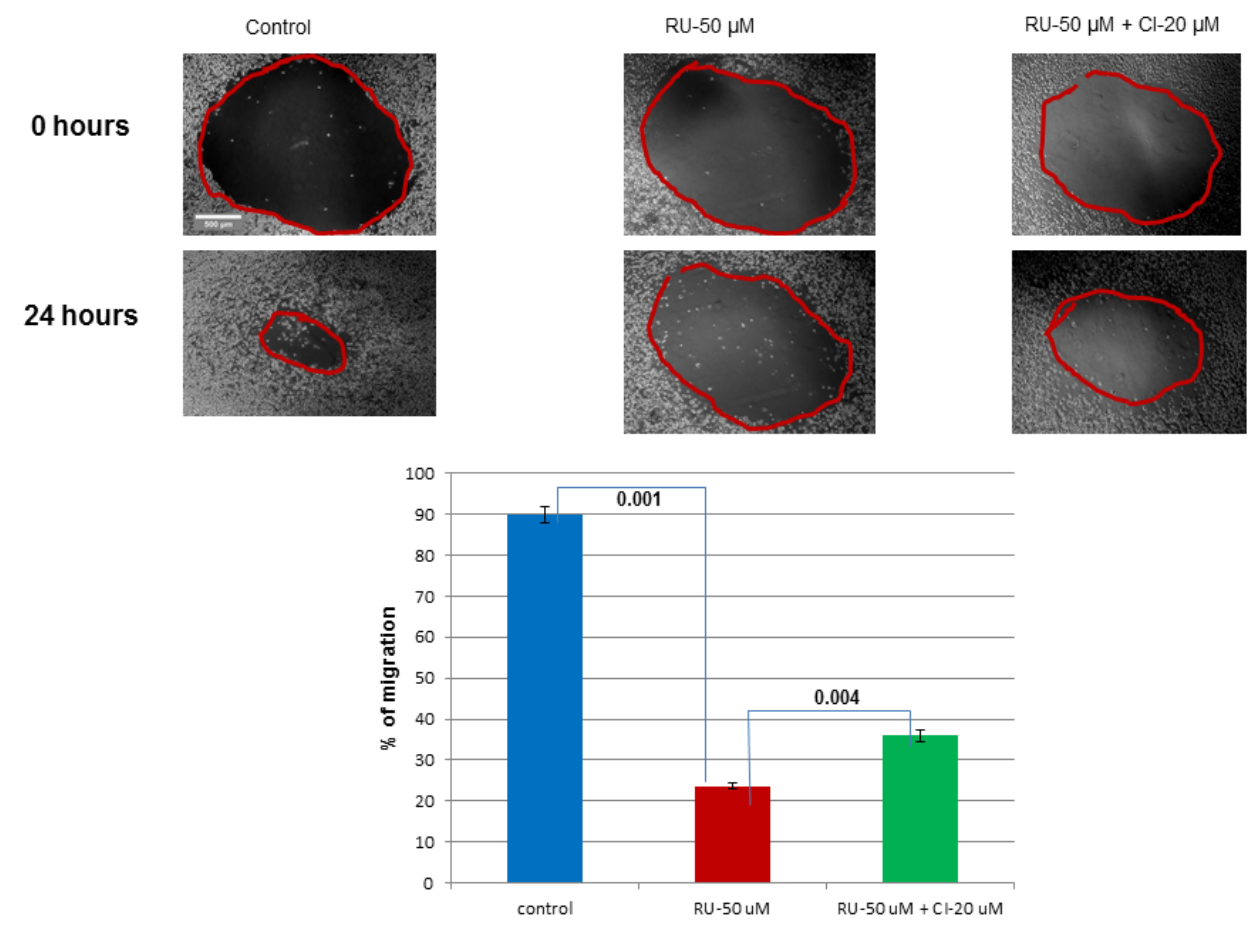

Figure 6. In-vitro rescue of migration function: As there were effects of RU-486 treatment on cell growth and adhesion functions, effect on migration function was checked. Migration assay was shown qualitatively by the picture between $0 \mathrm{hr}$ and $24 \mathrm{hrs}$ time period. Migration assay was also shown quantitatively by the bar diagram. RU-486 treatment affected migration ( $23.6 \%)$ significantly as shown by a p-value of 0.001 between control and RU-486 treated cells. But, CI was able to partially rescue (35.9\%) migration function. 
Ramaraj P (2018) In-vitro anti-cancer actions of RU-486 on human melanoma cells based on RU-486 treated, caspase inhibitor rescued and recovered cell growth, adhesion and migration functions

treatment of RU-486. Preliminary, cell growth recovery study showed that RU-486 treated cells marginally recovered cell growth after $72 \mathrm{hrs}$ of recovery. Initial time and dose-curve studies of adhesion function showed an optimal 24 hrs of incubation with RU-486 and an optimal concentration of $50 \mu \mathrm{M}$. These preliminary results gave the idea to rescue RU-486 treated cells with CI by suppressing apoptosis [7]. Results from the rescue experiments led to recovery experiments and to compare cell growth, adhesion and migration functions among all three experimental groups (treated, rescued and recovered).

In the rescue and recovery studies on cell growth, RU-486 treatment decreased cell growth to $61.5 \%$, compared to untreated control cell growth at $100 \%$. However, CI was able to rescue cell growth to $72 \%$. Both RU-486 treated and CI rescued cells were allowed to recover for $48 \mathrm{hrs}$. Initially cell growth increased to $70 \%$ in treated cells and $95 \%$ in rescued cells. When both groups were allowed to recover for a second $48 \mathrm{hrs}$, CI rescued cells showed a cell growth of $97 \%$, whereas RU-486 treated cells showed a moderate increase (77\%), indicating treated cells were still not able to recover cell growth completely even after 96 hrs of recovery.

In rescue and recovery studies on adhesion, RU-486 $50 \mu \mathrm{M}$ treated cells showed an adhesion of $64 \%$, whereas CI rescued cells showed an adhesion of $73.9 \%$. When RU-486 treated and CI rescued cells were allowed to recover for first $48 \mathrm{hrs}$, rescued cells showed an improved adhesion (95.9\%) over RU-486-treated cells (85.6\%). But, when both cells were allowed to recover for a second $48 \mathrm{hrs}$, both treated and rescued cells showed almost equal level of recovery in adhesion $91 \%$ and $98 \%$ respectively. This showed that suppression of adhesion by RU-486 was a reversible effect. Moreover, with RU-486 treatment, the effect on cell growth and adhesion function did not go hand in hand. As impairment in adhesion function affected migration function of BLM cells, RU-486 treatment decreased migration to $23.6 \%$. Whereas, CI partially rescued migration to $35.9 \%$, suggesting CI treatment was able to rescue migration function also.

Comparison of treated, rescued and recovered experiments on cell growth showed that CI rescued cells recovered better than RU-486 treated cells. RU-486 treated cells showed only a marginal recovery of cell growth over a period of $96 \mathrm{hrs}$, indicating recovery of cell growth was slow. Similarly, comparison of recovery studies of treated and rescued cells adhesion function indicated better recovery of adhesion in $\mathrm{CI}$ rescued cells. Moreover, recovery of RU-486 treated cells in the first $48 \mathrm{hrs}$ itself suggested that inhibition of adhesion was a reversible effect.

\section{Conclusion}

In conclusion, RU-486 treatment not only affected cell growth, but also adhesion and migration functions of human melanoma (BLM) cells, which were essential for metastasis of cancer. Moreover, RU-486 effect on cell growth was long-lasting as the cells did not recover completely even after $96 \mathrm{hrs}$ of recovery. In addition, CI rescue experiments further confirmed that the mechanism of inhibition of cell growth was due to apoptosis as reported earlier [7]. Since, RU-486 not only affected cell growth but also adhesion and migration functions, RU-486 had the potential to be an anti-cancer agent for melanoma treatment.

\section{References}

1. Weiss BD (1993) RU-486: The progesterone antagonist. Arch Fam Med 2: 63-70.

2. Baulieu EE (1991) The steroid hormone antagonist RU-486: Mechanism at the cellular level and clinical applications. Endocrinology and metabolism clinics of North America 20: 873-891.

3. Ulmann A (1987) The antiprogestins: A recent advance in fertility regulation. $J$ steroid biochem 27: 1009-1012.

4. Brandhagen BN, Tieszen CR, Ulmer TM, Tracy MS, Goyeneche AA (2013) Cytostasis and morphological changes induced by mifepristone in human metastatic cancer cells involve cytotoskeletal filamentous actin reorganization and impairment of cell adhesion dynamics. BMC cancer 13: 35 .

5. Taplin ME, Manola J, Oh WK, Kantoff PW, Bubley GJ, Smith M, et al. (2008) A phase II study of mifepristone (RU-486) in castration-resistant prostate cancer, with a correlative assessment of androgen-related hormones. BJU Int 101: 1084-1089.

6. Ramaraj P (2014) Cox JL. In-Vitro Effect of sex steroids on mouse melanoma (B16F10) cell growth. Cell Bio 3: 60-71.

7. Ramaraj P (2016) In-vitro inhibition of human melanoma (BLM) cell growth by progesterone receptor antagonist RU-486 (Mifepristone). JCT 7:1045-1058;

8. Ramaraj P, Cox JL (2014) In-vitro effect of progesterone on human melanoma (BLM) cell growth - Int J Clin Exp Med 7: 3941-3953 [Crossref].

9. Leder DC, Brown JR, Ramaraj P (2015) In-vitro rescue and recovery studies of human melanoma (BLM) cell growth, adhesion and migration functions after treatment with progesterone. Int J Clin Exp Med 8:12275-12285. [Crossref].

10. Mosmann T (1983) Rapid colorimetric assay for cellular growth and survival application to proliferation and cytotoxicity assays. J Immunol Methods 65: 55-63.

11. Ruan JS, Liu YP, Zhang L, Yan LG, Fan FT, Shen CS, et al. (2012) Luteolin reduces the invasive potential of malignant melanoma cells by targeting $\mu 3$ integrin and the epithelial-mesenchymal transition. Acta Pharmacologica Sinica 33:1325-1331.

12. Ratheeshs A, Ingle A, Gude RP (2007) Pentoxifylline modulates cell surface integrin expression and integrin mediated adhesion of B16F10 cells to extracellular matrix components. Cancer Biology and Therapy 6: 1743-1752.

13. Liang CC, Park AY, Guan JL (2007) In vitro scratch assay: a convenient and inexpensive method for analysis of cell migration in vitro. Nature Protocols 2: 329-333.

Copyright: (C2018 Ramaraj P. This is an open-access article distributed under the terms of the Creative Commons Attribution License, which permits unrestricted use, distribution, and reproduction in any medium, provided the original author and source are credited. 